\title{
Clinical Leadership as an Agent for Change: A Health System Improvement Intervention in Curaçao
}

This article was published in the following Dove Press journal: Journal of Multidisciplinary Healthcare

\author{
Jamiu O Busari $\mathbb{D}^{1,2}$ \\ Huriye Yaldiz ${ }^{3}$ \\ Reinold OB Gans (iD) 4 \\ Ashley J Duits (D) ${ }^{5-7}$ \\ 'Department of Pediatrics, Horacio \\ Oduber Hospital, Oranjestad, Aruba; \\ ${ }^{2}$ Department of Educational \\ Development and Research, Faculty of \\ Health, Medicine and Life Sciences, \\ University of Maastricht, Maastricht, the \\ Netherlands; ${ }^{3}$ Faculty of Medical \\ Sciences, Radboud University Nijmegen, \\ Nijmegen, the Netherlands; ${ }^{4}$ Department \\ of Medicine, University Medical Center \\ Groningen, Groningen, Netherlands; \\ ${ }^{5}$ Red Cross Blood Bank Foundation, \\ Willemstad, Curaçao; ${ }^{6}$ Institute for \\ Medical Education, University Medical \\ Center Groningen, Groningen, the \\ Netherlands; ${ }^{7}$ Department of Medical \\ Education, Curaçao Medical Center, \\ Willemstad, Curaçao
}

Introduction: The healthcare system in Curaçao is complex, fragmented, and poorly organized and typifies a system in a resource-limited environment. Deficits in competencies and local cultural barriers are factors that hinder sustainable healthcare in such settings and a failure to meet WHO sustainable development goals. This study reports the potential costeffectiveness and improved health outcomes of the first stage of a healthcare improvement project. The intervention, which is a multidisciplinary team-based leadership training program (MLP), reflects a promising strategy to tackle local healthcare needs.

Methods: A Multidisciplinary group of healthcare professionals in St. Elisabeth hospital, Curaçao, was selected to 1) participate in the MLP and 2) co-design a healthcare pathway on the management of decubitus ulcers. Using a qualitative research methodology, we conducted interviews to assess the perceived leadership growth, teamwork, and the barriers to the introduction of the new care pathway in their setting. Six themes were identified that explained the perceived leadership development and interprofessional collaboration. These included 1) Professional background, 2) Healthcare pathway design, 3) Resources, 4) Personal development, 5) Collaboration 6) Execution.

Conclusion/Implication: The participants valued the interdisciplinary approach of this health improvement project and acknowledged the added value of a training program that also addressed personal growth. This study shows how MLPs for health professionals can also serve as catalysts for health improvement efforts in resource-limited environments.

Keywords: medical leadership, care pathway, resource-limited environment, interprofessional, collaboration

\section{Introduction}

Since the turn of the millennium, aging populations, increased longevity, and chronic health problems have defined major public health issues in many countries worldwide. The impact of these events on the infrastructure of many health systems has been felt, with increased demands on medical and social services, especially in countries with limited financial possibilities in Africa, Asia, Latin America and the Caribbean. Some of the challenges these nations face include the lack of well-functioning healthcare systems, poor healthcare infrastructure and lack of well-trained healthcare providers. In most societies and especially in resource-limited environments, fragmented healthcare systems have created serious healthcare challenges, the outcome of which has included poor quality of service, irrational and inefficient use of resources, unnecessary increases in production costs, and increased consumer dissatisfaction. ${ }^{1}$
Correspondence: Jamiu O Busari

Tel +31 654945539

Email Jamiu.Busari@maastrichtuniversity.nl
Journal of Multidisciplinary Healthcare 2020:13 787-798 


\section{Context of the Need for Change}

While no single model of healthcare delivery has been proven to be effective in Small Island Developing States (SIDS), the value-based healthcare delivery has been proposed as a model that can possibly lead to sustainable healthcare in SIDS. For this to happen, however, the commitment and collaboration of the various stakeholders in healthcare are crucial. From what we know, collaboration among stakeholders is fundamental in designing and implementing the measures needed to effectively monitor patient-valued outcomes of key medical conditions in communities. ${ }^{2}$ The successful implementation and evaluation of these measures, however, require clinical leadership that is grounded in inter-professional collaboration and mutual respect among healthcare providers. ${ }^{2-4}$ The process also requires a mechanism that can spot deficits in the competencies of healthcare providers and identify local cultural barriers that hinder optimal performance. Finally, concrete interventions like (multidisciplinary) leadership training are needed to foster the development of clinical leadership, process ownership and the improvement of healthcare outcomes. ${ }^{4}$

\section{Healthcare Delivery in Curaçao}

Curaçao is a Dutch Caribbean island with an estimated population of 150,563 inhabitants..$^{5}$ The island has a relatively high prevalence of chronic diseases (e.g. diabetes, obesity, hypertension), poorly distributed financial resources and insufficient human capital to guarantee optimal healthcare delivery. Consequently, new and improved models of care are needed that can satisfactorily address the urgent health demands of the community. ${ }^{4}$ At the time of this study, the main general hospital currently serving the community in Curaçao was the St. Elisabeth Hospital (SEHOS). With its 300-bed capacity, the SEHOS provided secondary and tertiary health services to the inhabitants of the island in all major clinical specialties including adult, pediatric, and neonatal intensive care. The hospital was also a teaching institution with affiliations to primarily the University Medical Center Groningen and a couple of other tertiary medical institutions in the Netherlands and provided accredited residency and pre-residency training for Dutch medical training programs. ${ }^{6}$

Similar to the context of any developing country, the organization of healthcare in Curaçao, is complex, fragmented and unsynchronized. This is reflected by a highly inefficient healthcare system with a major emphasis on the delivery of curative care. The focus of the system's operational processes, therefore, is mostly on cost containment and less on the improvement of care process, innovation and the optimal organization of the health systems. ${ }^{7,8}$ This current situation, therefore, calls for an urgent need for change. Over the past decade, we conducted several studies that have shown the strategic benefits of competency-based training in Curaçao and how it could contribute to workforce capacity development and healthcare system improvement. ${ }^{6,7}$ These studies have also identified specific conditions needed to successfully implement healthcare change initiatives in a resource-limited environment like Curaçao. ${ }^{4}$

\section{The Healthcare Improvement Project}

In 2018, we set up a healthcare improvement project that was based on the knowledge and experience we had garnered from more than a decade's work in Curaçao. ${ }^{4,6}$ The aim of this project was to create a unique health improvement program tailored to address critical healthcare issues in Curaçao. As a first step of this healthcare improvement project, we chose a design that was based on 1) recommendations from an earlier case study we conducted on the implementation of a competency-based health system in Curaçao and on 2) the results from earlier research on interprofessional collaboration. ${ }^{2,7}$

Decubitus (or Pressure) Ulcer was the critical healthcare issue $(\mathrm{CHCI})$ that we selected for the project reported in this paper. This health condition was considered a serious health challenge for patients in SEHOS and is recognized as one of the main quality parameters of hospital care within the Dutch healthcare system. ${ }^{9}$ We also selected a mixed team of health professionals for the project, all of whom were actively involved in the selection and development of the chosen care pathway. ${ }^{4}$ The objective of this first stage of the healthcare improvement project was to demonstrate the potential cost-effectiveness and improved health outcomes of our targeted intervention. In addition to developing a project to address the care of decubitus ulcers, we planned to investigate the growth in participants' leadership abilities and how they perceived the value of improved interprofessional collaboration. We were also interested in knowing the extent to which observed outcomes could be attributed to the leadership training and/or the care pathway development. 


\section{Methodology}

Our approach was divided into two separate processes, which included 1) workforce resource development and 2) focused healthcare improvement with predefined outcomes. The outcomes included a multidisciplinary and team-based leadership development program for professionals and the creation of an intervention to address the care pathway for decubitus ulcer (Figure 1).

The fieldwork was conducted between May 2017 and May 2018 at SEHOS, Curaçao. We chose to select participants with different backgrounds/professions for inclusion in the project. Twenty-five out of the 33 enrolled participants completed the year-long clinical leadership training program, however the whole of group of thirtythree was involved in the design of the decubitus ulcer care pathway. The Clinical leadership program was run over a 12-month period and comprised of 3 teaching blocks with two Blocks (1 and 3) containing instructional modules (see box 1) and workshops and Block 2 dedicated to the development of the CHCI intervention i.e. Decubitus ulcer pathway.

Our goal was to examine the respondents' perceived growth in leadership abilities and how much of this could be attributed to the leadership training and/or care pathway development. We were also interested in identifying, if any, what the perceived benefits/experiences of the
Box I Contents of the Leadership Curriculum

\begin{tabular}{|l|l|l|}
\hline Block I & Block 2 & Block 3 \\
\hline - Value Based & Development of a Quality & - Sharing \\
Healthcare & Improvement intervention in one of & experiences \\
- Leadership or & four health care domains: [Decubitus & - Analyzing \\
Management & ulcer, Hypertension, Obesity, Child \& & Results of Care \\
- Achieving & maternal care] & Learning from \\
Excellence & & failure \\
- Authentic & & $\begin{array}{l}\text { Compassionate } \\
\text { Leadership }\end{array}$ \\
Leadership & & - Multidisciplinary \\
Quality of & & Teamwork \\
Care \& Safety & & $\bullet$ Effective \\
Basics of & & Negotiation \\
Quality of & & High Impact \\
Improvement & & Leadership \\
- Measuring & & Dry-runs \\
Quality & & \\
Indicators & & \\
- Project & & \\
Management & & \\
\hline
\end{tabular}

interprofessional collaboration were in the process of developing the care pathway. For this purpose, we chose to use a qualitative approach with the help of interviews to obtain the needed information. The interviews were semistructured, and a standardized list of items were used to guide the conversations and questions during the

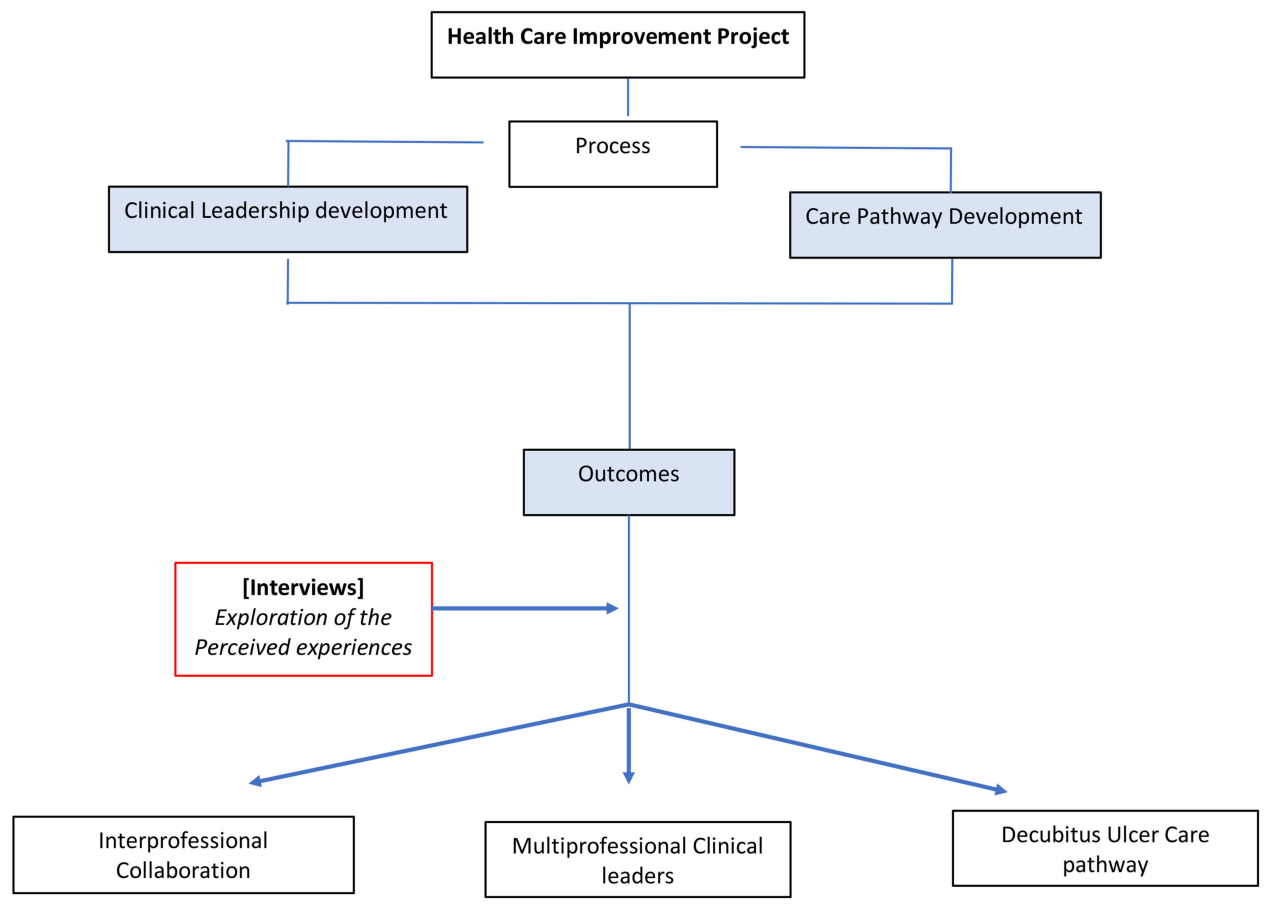

Figure I Flowchart of the healthcare improvement project. 
encounters. We approached all of the participants to participate in the post-implementation evaluation, and ten of them were able, and gave consent to participate in the interviews. Logistical reasons such as leaves of absence, clinical duties and the short time frame within which the interviews could be done contributed to the decision to limit the number to 10 .

All of the interviews were audiotaped and transcribed verbatim by one of the researchers (HY). These transcripts were later used for thematic content analysis, to identify critical elements in the responses and allow comparison and categorization of the respondents' perspectives. ${ }^{10} \mathrm{We}$ manually constructed the coding schemes used to identify the (sub) themes. ${ }^{11}$ An inductive analysis process, with open codes, was used as we were interested in knowing the impact of the multidisciplinary leadership training as an agent for change. ${ }^{12}$ Three researchers (HY, JB, AJD) reviewed the (sub) themes separately and agreement on conflicting themes was achieved through consensus. The participants were provided the opportunity to review the summaries of their individual interviews and provide feedback on the data prior to final analysis. They could verify if our findings truly emerged from the data analysis and their feedback provided us with the additional credibility for our research. ${ }^{13}$ All quotes were translated from Dutch to English and were used to support the identified themes from the analysis. ${ }^{13}$ The identified themes, explaining leadership and interprofessional collaboration included: 1) Professional background, 2) Healthcare pathway design, 3) Resources, 4) Personal development, 5) Collaboration 6) Execution.

\section{Ethical Considerations}

All participants indicated their willingness to participate in the interviews voluntarily. They were informed about the objectives of the study by the researchers and they all gave informed consent before taking part in the interviews. To ensure confidentiality, written transcripts of the interviews and data analysis were performed anonymously. Ethical approval was sought and given by the SEHOS medical ethical board on March 1, 2017.

\section{Results}

As described above, 10 participants accepted the invitation to participate in the interviews to evaluate the impact of the intervention to design a care pathway for decubitus ulcers and of the training program "clinical leaders as agents for change". Table 1 contains an overview of the
Table I Demographics of the Participants

\begin{tabular}{|l|l|l|}
\hline Variable & $\begin{array}{l}\text { Total Group } \\
(\mathbf{N}=33)\end{array}$ & $\begin{array}{l}\text { Interview } \\
\text { Group (N=10) }\end{array}$ \\
\hline Gender: & 7 & \\
Male & 26 & 8 \\
Female & & \\
\hline Profession: & 5 & 2 \\
Medical specialist & 15 & 3 \\
Nurse & 8 & 2 \\
Paramedical professional & 5 & 3 \\
Management \& educational staff & 5 & \\
\hline Participation in previous & & 6 \\
leadership course: & 25 & 4 \\
Yes & 8 & \\
No & & \\
\hline
\end{tabular}

demographic characteristics of the participants interviewed as well as the total group of participants in the project.

Six themes were differentiated after our data analysis and reflected how the participants experienced the leadership training and interprofessional collaboration while developing the healthcare pathway for decubitus (see Table 2).

Below is a description of each individual theme from the data analysis:

\section{Theme I: Professional Background}

This theme provided an overview of the perceived diversity and multidisciplinarity of the group. The composition of the group included a dietitian, a physiotherapist, medical specialists (intensive care physician, orthopedic surgeon), nurses from different wards, representatives of the hospital's quality assurance department and nursing leadership staff (Table 1). All of the participants described relevant prior professional experiences and most of them had previous experiences in management and leadership functions $(\mathrm{N}=7)$. These experiences were diverse, ranging from collaboration in multidisciplinary boards or groups, to formal education in healthcare management. Approximately half of the participants had participated previously in some form of clinical leadership training provided by the SEHOS.

\section{Theme 2: Healthcare Pathway Design}

Within this theme different topics became apparent, namely shortcomings in the design of the current decubitus 
Table 2 Overview of the Themes and Frequency of Recommended Subthemes

\begin{tabular}{|c|c|c|}
\hline Main Theme & Sub Theme & $\begin{array}{l}\text { Participant Who Mentioned } \\
\text { This }\end{array}$ \\
\hline \multirow[t]{2}{*}{ Professional background } & Group composition & $\mathrm{I}, 2,3,4,5,6,7,8,9,10(\mathrm{~N}=10)$ \\
\hline & Prior professional experiences in management and leadership & $\mathrm{I}, 2,3,4,5,8,9,10(\mathrm{~N}=8)$ \\
\hline \multirow[t]{5}{*}{ Healthcare pathway design } & $\begin{array}{l}\text { Shortcomings in the process of designing the decubitus healthcare } \\
\text { pathway }\end{array}$ & $\mathrm{I}, 2,3,4,5,6,7,8,9,10(\mathrm{~N}=10)$ \\
\hline & Group characteristics & $\mathrm{I}, 3,4,5,6,8,10(\mathrm{~N}=7)$ \\
\hline & Experiences & $\mathrm{I}, 2,3,4,5,6,7,8,9,10(\mathrm{~N}=10)$ \\
\hline & Attitude & $2,3,4,5,6,7,8,10(N=8)$ \\
\hline & Bureaucracy & $5,8,9,10(N=4)$ \\
\hline \multirow[t]{4}{*}{ Resources } & Materials & $\mathrm{I}, 2,3,4,5,6,8,9,10(\mathrm{~N}=9)$ \\
\hline & Human resources & $\mathrm{I}, 2,4,5,6,8,10(\mathrm{~N}=7)$ \\
\hline & Financial resources & $3,4,6,8,10(N=5)$ \\
\hline & Creativity & $5,8,9,10(N=4)$ \\
\hline \multirow[t]{3}{*}{ Personal development } & Leadership in practice & $\mathrm{I}, 6,7(\mathrm{~N}=3)$ \\
\hline & Insight into others and their responsibilities & $\mathrm{I}, 2,3,4,5,6,8,10(\mathrm{~N}=8)$ \\
\hline & Self-development & $\mathrm{I}, 2,4,5,6,9(\mathrm{~N}=6)$ \\
\hline \multirow{6}{*}{$\begin{array}{l}\text { Collaboration: Transparency and } \\
\text { communication }\end{array}$} & Collaboration strategies & $\mathrm{I}, 2,3,4,5,6,7,8,9,10(\mathrm{~N}=10)$ \\
\hline & Hierarchy & $\mathrm{I}, 4,5,6,10(\mathrm{~N}=5)$ \\
\hline & Personal point of view & $2,3,5,6,7,8,9,10(\mathrm{~N}=8)$ \\
\hline & Communication skills & $2,5,6,7,9,10(N=6)$ \\
\hline & Openness and transparency in communication & $\mathrm{I}, 2,3,4,5,6,7,8,9,10(\mathrm{~N}=10)$ \\
\hline & Improvement of multidisciplinary collaboration & $\mathrm{I}, 4,5,6,7,8(\mathrm{~N}=6)$ \\
\hline \multirow[t]{10}{*}{ Implementation } & Digitalization and innovation & $4,5,6,7,8,9(\mathrm{~N}=6)$ \\
\hline & Long term expectancies & $\mathrm{I}, 3,4,5,6,(\mathrm{~N}=5)$ \\
\hline & Contribution during implementation & $\mathrm{I}, 2,3,4,5,6,7,8,9,10(\mathrm{~N}=10)$ \\
\hline & Education & $2,3,4,5,6,7,8,9,10(\mathrm{~N}=9)$ \\
\hline & Evaluation & $\mathrm{I}, 2,4,5,7,8,10(\mathrm{~N}=7)$ \\
\hline & Evidence based practice & $4(N=1)$ \\
\hline & Patient centred care & $\mathrm{I}, 3,5,6,8(\mathrm{~N}=5)$ \\
\hline & Concerns about implementation & $2,3,4,5,6,7,8(\mathrm{~N}=7)$ \\
\hline & Broad support & $\mathrm{I}, 2,3,4,5,6,7,8,9,10(\mathrm{~N}=10)$ \\
\hline & Organizational requirements for successful implementation & $2,4,5,6,7,8,10(\mathrm{~N}=7)$ \\
\hline
\end{tabular}

ulcer care pathway, experienced collaboration during the development of the decubitus healthcare pathway, attitude of the group members, and the role of bureaucracy.
All of the participants mentioned some form of shortcoming in the process of designing the decubitus healthcare pathway. The most cited limitation was the difficulty 
in getting the team together to meet regularly, as most of them had different work shifts. Due to scheduling conflicts, it was difficult to find moments that matched with their different availabilities for a meeting. Half of the participants mentioned that communication from the project leaders was often late. They mentioned that there was a need for more guidance during projects like the decubitus pathway $(\mathrm{N}=2)$ that the duration of the first part of the decubitus pathway project could have been shorter $(\mathrm{N}=2)$ and that last-minute changes in planning by the project leaders should be avoided or minimized $(\mathrm{N}=5)$

The majority of the participants also mentioned some multidisciplinary activities of the group, which would have benefited from a lesser number of sub-groups, fewer members per group, and prevented the observed dropout of group members. All the participants mentioned new experiences gained from participation in the development of the decubitus healthcare pathway. Eight participants explicitly valued the multidisciplinary collaboration used to design a healthcare pathway. A couple $(\mathrm{N}=2)$ of participants described the multidisciplinary collaboration as efficient, structured, and a pleasant way to bring theory into practice.

Almost all of the participants mentioned the collaborative attitude of the group members, which was described as dynamic, active and enthusiastic. Almost half of the participants said that group members were very committed and put in a lot of effort.

Meeting up was difficult, especially at the beginning of the project. But the group was very dedicated. If some could not make it to the meetings because of their shifts, most of them would make an effort just to drop by, at least for a brief moment.

Respondent 6 about attitude of the group members (Theme 2)

\section{Theme 3: Resources}

Almost all of the participants identified problems concerning resources i.e. human resources, materials as well as financial resources. Of these three topics, the most mentioned resource problem was the problem of limited availability of anti-decubitus materials. This was experienced by all but one of the participants. Half of the participants also claimed that the quality of the materials they had were not always sufficient. One mentioned that she would like more options for the same materials. Materials in sufficient amount and of good quality were referred to as preconditions for a good implementation of the care pathway.

Ideally, our hospital would have all the sufficient materials for the best care. However, we have shortages, but this stimulates us to think outside the box and to be innovative. You cannot tell your patient or his family that you cannot take good care of the patient due to shortages of materials. They do not need to know that, they just want the best possible care.

Respondent 5 about limited materials (Theme 3)

Adequate workforce was another issue mentioned by approximately three quarters of the participants. The hospital was understaffed according to them. About a third of the participants said that understaffing led to having less time to attend to each patient adequately. One participant mentioned that understaffing (insufficient workforce) led to a perceived higher workload. One proposed the introduction of "care assistants" to help in distributing meals to the patients, to lower the workload of the nurses and to make sure that the patients at risk for decubitus were eating enough.

According to half of the participants, the problems with staffing and materials were the result of financial shortcomings of the hospital. Despite these shortcomings, according to approximately half of the participants, this situation at the same time stimulates creative and out of the box thinking.

\section{Theme 4: Personal Development}

Within this theme three topics were derived, namely "leadership in practice", "insight into others and their responsibilities", and "personal development". A third of the participants mentioned the first topic, leadership in practice. They stated that they had developed their own view on good leadership. Qualities of a good leader were honesty, leading by example, putting guidelines into practice, having a helicopter view on events, and honoring your commitments.

A majority of the group told that they gained more insight into the perspective of others and their responsibilities as a result of interprofessional collaboration during the development of the care pathway. Almost all of them mentioned that they realized the importance and interests of other disciplines during the interprofessional brainstorm sessions. Some also claimed to have a better understanding of problems others are facing. In some cases, these insights led to better understanding and more consistency in following up on advices of other healthcare 
professionals outside the care pathway under development.

Furthermore, about a third of the participants gained insight into the organization and management of general processes within the hospital and patient care in particular.

This project made me realize I had a blind spot. You only see the things, you are directly involved in. For example, with decubitus care, I noticed during this project that there was not sufficient amount of materials, like decubitus matrasses. But also, that processes, such as consulting dieticians when patients at risk get hospitalized, were not optimal. For me, it just became apparent: We are not as far as we want to be concerning decubitus care.

Respondent 7 about insight into others and their responsibilities (Theme 4)

It is nice to have input from other professions. Every profession has their own issues and competences. Therefore, it is very effective to tackle problems multidisciplinary and interprofessionaly.

Respondent 3 about insight into others and their responsibilities (Theme 4)

It is nice to be able to contribute to such a project, since it enables me to use my prior experiences within nursing and management. This project also provided me a clearer picture of the organization within our hospital and the organization concerning patient care, besides the thing you do already know from your clinical experiences on hospital wards. Altogether, you come to realize how patient care in general should be organized.

Respondent 2 about insight into others and their responsibilities (Theme 4)

The last topic within this theme was personal development, which was mentioned by two-thirds of the participants. The responses differed with respect to what they gained personally, for example, one participant claimed to have learned more about the process of giving and receiving feedback, while another gained insight into critically appraising personal goals and learning objectives. Another participant stressed the importance of constantly improving yourself while two acknowledged having learnt more about decubitus ulcers as a medical problem. Lastly, one of the participant's claimed to have gained new insights and knowledge about her own leadership and coaching strategies.

Every year we sit and talk about quality of healthcare.

With the project on the care pathway for decubitus, we finally took some action to improve it. During my career, I participated in quite some projects, mostly solely based on theory. Within this pathway theory and practice came together, which I really liked.

Respondent 1 about personal development (Theme 4)

\section{Theme 5: Collaboration}

Within the theme "collaboration" the following 6 topics were discussed: collaboration strategies, hierarchy, personal point of view, communication skills, openness and transparency in communication and the improvement of interprofessional collaboration. The analysis of the respondents' comments revealed that a variety of strategies were used to collaborate with each other. The strategies that were most mentioned included preparing for meetings in personal time (also referred to as having homework), ensuring an interprofessional composition of participants during the brainstorm sessions to ensure discipline-related input (expertise) and to stimulate reflection on the generic features of a leadership environment. Fewer mentioned strategies, though not less important, were setting goals, honoring agreements and taking on responsibility. The specific role of each member was different, although there mostly was no explicit role assignment. Some terms used to describe their roles included coordinator, leader, organizer, secretary, representative, and implementor.

Everybody had their own responsibilities and tasks. When we all gathered, everybody had completed their part, so that we could brainstorm all together about the task ahead.

Respondent 7 about collaboration strategies (Theme 5)

Our group divided all the tasks. Everybody took care of their own part. When we gathered, we combined all the parts to get to a plan of action. This was a nice approach, because you split every large task into smaller pieces per person, which lowered the workload for each.

Respondent 8 about collaboration strategies (Theme 5)

It is more effective to address every issue during meetings, rather than splitting up the project into the tasks 'as a piece of homework'. Since you can brainstorm about the problem as group and then tackle it directly instead of squeezing it in after work with all the other things you still need to do.

Respondent 3 about collaboration strategies (Theme 5)

The second topic "hierarchy" pertained to the influence of hierarchy within the hospital. Due to the 
interprofessional nature of this project, approximately half of the participants felt that the perceived hierarchy decreased significantly within the team. However, a few others claimed that hierarchy still played a significant role within the hospital at large. One participant mentioned that hierarchy was hampering feedback.

There is a hierarchical culture in the hospital: at the top there are medical specialists, and at the bottom the nurses and, last, the patients? During this project we had an interprofessional and multidisciplinary group with medical specialists, nurses and paramedics in which everyone was equal. By working together, the hierarchy and the gap between different professions decreased.

Respondent 1 about hierarchy (Theme 5)

More than half of the participants said that the group members all had their own personal ideas and thoughts about decubitus care. This was not considered to be a problem, but rather a valuable input to solve the problem. A third of the participants stated that everybody was an expert with respect to their own professional expertise. Differences in point of view or disagreements were not viewed as obstacles, because of the way each participant communicated with the others. Two-thirds of the participants said that everyone showed respect for the other participants even though people did not necessarily agree with each other. This strategy led to a safe learning environment in which openness was encouraged and everyone's opinion was valued. Another often mentioned strategy was listening and paying attention to the opinions of others. "Summarizing" as a communication skill was mentioned once. All participants, except for one, mentioned comments related to openness and transparency in communication. Lack of communication about the care pathway and its envisioned implementation with the rest of the hospital staff remained a large concern. The participants would like to see more open, transparent and clear communication. The mission and strategy concerning the healthcare pathway should be more clearly emphasized by the Hospital board. Some mentioned that there was also need for better documentation and transfer of information.

According to most of the participants, the interprofessional collaboration improved since they started working together on the care pathway. They got to know different professionals, with whom they did not have any or much contact before. Because they got to know each other better there was more work-related conversation as well as informal friendly discussions. They described it as improved and more open communication with other disciplines. This also led to improved and increased collaboration between these healthcare professionals besides the development of the care pathway as described by one respondent.

Collaborations brings people together. Collaboration in its turn leads to better communication. Not only within the meetings of this project but also outside the boundaries of this project, for example, when you come across each other down the hallways of the hospital.

Respondent 1 about improvement of interprofessional collaboration (Theme 5)

\section{Theme 6: Execution}

Within this main theme participants expressed a number of factors that they thought were crucial for the successful execution of the care pathway and how they could serve as enablers or barriers for the implementation of the care pathway within the organization. These factors were described as: digitalization and innovation, long-term expectations, role of the project team during implementation, education, evaluation, evidence-based practice, patient-centered care, concerns about implementation, broad support and organizational requirements for successful implementation. With a planned move to a new hospital facility, the participants expected the facility to be modern, with more digital communication. They expected that the care pathway will be digitized and accessible from each computer, patient folders to be digitally available and online surveys to get and provide feedback from and to the hospital staff. One person mentioned that working in a digital environment would lead to more sustainability and was more environmentally friendly since less paper would be needed. Two stressed the importance of the need to innovate continuously.

For the long-term, different expectations arose from the participants. Around a third of the participants expected that more care pathways will be developed and implemented. Two participants suggested that the healthcare pathway will eventually be implemented transmurally. One person mentioned the introduction of management teams and improved care efficiency through the use of culturesensitive healthcare pathways and improved interprofessional collaboration.

Thirdly, all participants were asked about what they thought they could contribute during the implementation 
phase. Contributions mentioned by 4 people were: to offer help during the evaluation, monitoring during implementation, providing feedback, stressing the importance of the healthcare pathway to other colleagues, motivating others to use the decubitus care pathway, and participating actively and using the decubitus healthcare pathway consistently themselves.

Finally, informing and training for employees was thought of as being of importance by almost all of the participants. Some believed that training and informing should not happen once, but repeatedly. Approximately half of the participants recommended succinct visual documentation of the steps of the healthcare pathway ("Infographic"), so the information could be looked up easily and quickly. One stated that the training should be personally appealing and catchy in order to make it more interesting for the employees to use the healthcare pathway.

Hand-outs are essential for the implementation. One form on which you can see what to do within a glance. So, the information needs to be compact, clear and accessible.

Respondent 3 about information (Theme 6)

Another important aspect for implementation was the evaluation of the care pathway (what is the deliverable; when is the project a success?). Almost all of the participants agreed on this point. A couple of them also said that they wanted to evaluate themselves as collaborators and their own growth. Another aspect that was mentioned concerning the evaluation was that the first evaluation should take place as soon as possible following the start of the implementation for monitoring purposes. They also suggested that there should be a baseline measurement in order to track the progress, the progress and evaluation of the process should be reported, adjustments should take place swiftly when progress has not been as good as expected and that feedback should be given to the care professionals based on the results of evaluation.

One of the participants stressed the importance of evidence-based practice during the implementation of the healthcare pathway. Her point of view was that the latest knowledge in the field of decubitus in combination with best practices and best evidence should play a part during the implementation phase.

With the development of the healthcare pathway, you try to combine best practice and best evidence. This enables you to get to know about the newest technologies and newest developments in your field.
Respondent 4 about evidence-based practice (Theme 6)

Patient-centered care was also mentioned by half of the participants. They thought it was important to involve the patient during the implementation. This could be, for example, by interdisciplinary consultations that included patients. Some thought that not only the patient but also their family should be involved, because they could help in tackling the decubitus problem during hospital visits and after the patient is discharged from the hospital. One also thought that the patient should be central in this project, since the ultimate goal would be to deliver better decubitus healthcare to the patient. Lastly, one participant mentioned that the bond between physicians and patients should be improved: the doctor should be talking with the patient instead of talking about the patient in the presence of the patient.

Our human resources are limited, we do not have enough nurses around here. So, the family needs to be involved with the care for the patient. The family of the patient needs to know what is happening and how to act. For example, when visiting your grandmother at risk for decubitus, do not let your grandmother lay in her bed the whole time because she is sick, but also help her to sit in a chair for a moment, so she does not develop decubitus ulcers.

Respondent 3 about patient-centered care (Theme 6)

Although all participants were enthusiastic about the decubitus care pathway, most of them had certain doubts about its implementation. This was due to poor and insufficient dissemination of information about the project to the rest of the hospital staff. Another point was that there were more projects in the past, which had been designed but were never implemented. The participants were afraid that this healthcare pathway would end up on a pile of other initiatives and all their hard work would have been for naught. Another point of concern was the lack of supporting materials that could hamper consistent implementation. Nevertheless, they stayed ambitious hoping that it would turn out for the better this time.

All of the participants agreed upon the fact that there should be broad support in order to achieve a successful implementation. Some suggestions they gave to create broad support included a bottom-up approach, a shared vision, and acknowledging the importance of every single person. Some thought that implementation would be more successful when it was bottom-up or involving the opinion of other people than the project designers, since they 
would feel more involved rather than it being another order from the board.

In order to prevent surprises and resistance from the staff, you need to inform all the employees of the hospital about the status quo of this project.

Respondent 10 about broad support (Theme 6)

I do not like top down structure. Because 'their theories' do not fit 'reality in practice'. In order to make suitable and applicable changes, you need to involve people who are delivering care and not just the people behind desks.

Respondent 10 about broad support (Theme 6)

Lastly, within this main theme, some organizational requirements were needed for a successful implementation. A majority of the participants named this topic, but their requirements differed. Most of them felt that a fulltime leader with content expertise should be in charge to lead and monitor the implementation phase as most healthcare professionals were already too caught up with their primary tasks. Furthermore, there should be clear task assignments, so that everybody knows what he/she needs to do and is responsible for. Other requirements although less frequently mentioned were that someone was needed to monitor the progress structurally and one person should be available for when people were facing problems or questions related to the implementation of the care pathway. Finally, the care pathway should become part of the standing organization, which should be promoted and facilitated by the board of directors.

\section{Discussion}

The push toward interprofessional clinical and team-based practice arose from the recognition that the historically siloed approach to care delivery, in which representatives from different disciplines worked in parallel or sequentially rather than in collaboration, limited the efforts to effectively tackle long-standing challenges to optimize outcomes for patients and families. ${ }^{1}$ In this study, we investigated the perceived benefits of a healthcare improvement intervention, which was to design a decubitus ulcer care pathway ${ }^{4}$ and measure its impact on interprofessional collaboration. Specifically, we sought for perceived growth in leadership abilities and participants' perceived benefits/experiences from the interprofessional collaboration. The outcome of our study, the first stage of a health improvement initiative in Curacao, revealed various themes, which we categorized into professional background, healthcare pathway design, resources, personal development, collaboration/communication and implementation.

With respect to the design of the program, the group consisted of a mix of medical professionals involved in daily decubitus patient care. As reported by others, an effective mix of professionals is important for achieving effective healthcare pathway development. ${ }^{14}$ Teams composed of representatives from different disciplines have a better overview of local clinical and operational issues and can better address these issues in planning and change implementation. Our results showed that interprofessional team activities and collaboration resulted in better understanding among professionals. Great value was given by the participants to the collaborative attitude experienced in meetings supporting observations in other reports that collaboration within teams and the achievement of a collaborative attitude is a hallmark of interprofessional practice. ${ }^{14}$ Several relevant issues were highlighted in the design phase starting with the challenge to align individual schedules for effective team meetings. As also described by others, the hectic nature of inpatient care settings limited the available time for team meetings. ${ }^{14}$

The program stimulated in an interactive and effective way, the leadership competence of the individual participants and its importance for personal development. During the program meetings, the perceived hierarchical culture decreased over time. This welcome change was in accordance with the proposed requirements for safe healthcare environments and effective teamwork. ${ }^{15}$ As reported by us and others, respect and open communication were apparently an essential component of levelling hierarchy and promoting healthy and productive work environments. ${ }^{2,15}$ Regarding personal development, the topics mentioned by the participants (i.e. leadership in practice, insight into own and other responsibilities, and personal development) corroborated earlier recommendations indicating their relevance and importance for effective team performance. ${ }^{15,16}$ For the implementation phase of the project, valuable practical recommendations were given by the participants as a result of the design phase. The necessity of broad (management) support along with opportunities to apply the designed program were mentioned and agreed with recommendations in other studies. ${ }^{17}$

We also observed that the themes used in previous questionnaires $^{18}$ and lists ${ }^{19}$ to investigate the needs and requirements of interprofessional programs were 
mentioned by the participants of our study as well. We believe that the interactive and direct approach of the clinical leadership program was ideal for obtaining relevant information needed for improving interprofessional communication among healthcare professionals (2) in a small scale setting like ours needed to develop this. By involving and granting ownership to the participants in a guided interactive fashion, relevant themes directly applicable to the local situation were obtained. This approach thereby helped to circumvent the sometimesperceived non-ownership issues when using questionnaires. ${ }^{15}$

It is worthy to note that while we approached all of the participants for the post-implementation evaluation, only ten were able to participate. Logistical reasons such as leaves of absence, clinical duties and the short time frame within which the interviews could be done, accounted for the low number of respondents questioned. We acknowledge that self-selection can potentially disguise the inherent bias of participants however we believe the in-depth qualitative interviews and the richness of the comments, compensate for the relatively low number of participants interviewed. Finally, at the time of preparing this report, the decubitus ulcer care pathway was still in the early stages of implementation within the hospital system. As a result, there was insufficient data to describe the impact of the care pathway on the outcome of care.

\section{Conclusion}

The objective of the first stage of our healthcare improvement project was to demonstrate the potential costeffectiveness and improved health outcomes of a targeted intervention i.e. clinical leadership program. In the process, we reaffirmed that the achievement of interprofessional practice requires investing in the interprofessional education of trainees, practicing clinicians and other medical professionals. In situations where there is effective interprofessional collaboration, the general wellbeing of personnel and organizational engagement is enhanced. ${ }^{14}$ This project was unique in that it embraced the principles of value-based healthcare delivery, which we felt would effectively serve and sustain current and future healthcare challenges in Curaçao. We believe that the results of the design phase of the program provide a blueprint for other care pathways and fosters a climate of continuous improvement to meet ongoing patient needs. We also believe it will have an impact on achieving an effective value-based healthcare delivery system applicable to our local situation. ${ }^{20}$ The results described in this paper show the general applicability of this model in achieving a better understanding of the essential issues regarding interprofessional collaboration, as well as improving workflow within a healthcare system. Furthermore, it aligns with the Global Strategy for Human Resources for Health (HRH) 2030 call to strengthen interprofessional teamwork collaboration. ${ }^{21}$ Finally, by addressing the local culture and attitude for change beforehand, ${ }^{4}$ a suitable design phase could be more effectively constructed. Currently, the proposed key performance indicators for the design phase are being monitored and related data acquired as the study has moved into the implementation phase.

\section{Disclosure}

The authors report no conflicts of interest in this work.

\section{References}

1. PAHO. Integrated Health Service Delivery Networks: concepts, Policy Options and a Road Map for Implementation in the Americas. Washington, D.C.: Pan American Health Organisation; 2011. Available from: https:/www.paho.org/hq/dmdocuments/2011/ PHC_IHSD-2011Serie4.pdf. Accessed May 10, 2020.

2. Busari JO, Moll FM, Duits AJ. Understanding the impact of interprofessional collaboration on the quality of care: a case report from a small-scale resource limited health care environment. 10, 227. J Multidiscip Healthc. 2017;10(227):227-234. doi:10.2147/JMDH. S140042

3. Frenk J, Chen L, Bhutta ZA, et al. Health professionals for a new century: transforming education to strengthen health systems in an interdependent world. Lancet. 2010;376(9756):1923-1958. doi:10.10 16/S0140-6736(10)61854-5

4. van Boekholt TA, Duits AJ, Busari JO. Health care transformation in a resource-limited environment: exploring the determinants of a good climate for change. $J$ Multidiscip Healthc. 2019;12:173-182. doi:10.2147/JMDH.S194180

5. Central Bureau of Statistics C. First results Census 2011 - Curaçao. CBS. Demography of Curaçao: Publications series Census $2011 \mathrm{Web}$ site; 2014. Available from: https://www.cbs.cw/website/2011census_3226/item/demography-of-Curaçao-publication-series-census -2011_757.html. Accessed May 10, 2020.

6. Busari JO, Duits AJ. The strategic role of competency based medical education in health care reform: a case report from a small scale, resource limited, Caribbean setting. BMC Res Notes. 2015;8:13. doi:10.1186/s13104-014-0963-1

7. Busari JO. Quality Requirements of Competency Based Medical Care in Curaçao. (Kwaliteitseisen Voor Competentie Gestuurde Medische Zorg Op Curaçao). Willemstad: Dutch caribbean foundation for higher medical education (NASKHO); 2012.

8. Alberts JF, Gerstenbluth I, Halabi YT, O’Neil J. The Curaçao Health Study. Groningen: Northern Centre for Healthcare Research; 1996.

9. Inspectie Gezondheidszorg en Jeugd [Inspectorate of Healthcare and Youth]. Basisset Medisch Specialistische Zorg Kwaliteitsindicatoren 2020 [Basic Set medical specialists quality of care indicators, 2020]. Utrecht: Ministerie van volksgezondheid, welzijn en sport; 2019. Dutch.

10. Ritchie J, Lewis J, Nicholls CM, Ormston R. Qualitative Research Practice: A Guide for Social Science Students and Researchers. London: Sage; 2013. 
11. Green J, Thorogood N. Qualitative Methods for Health Research. Lomdon: Sage; 2004.

12. Elo $\mathrm{S}$, Kyngäs $\mathrm{H}$. The qualitative content analysis process. $J A d v$ Nurs. 2008;62(1):107-115. doi:10.1111/j.1365-2648.2007.04569.x

13. Shenton AK. Strategies for ensuring trustworthiness in qualitative research projects. Educ Inf. 2004;22:63-75. doi:10.3233/EFI-2004-22201

14. Baird J, Ashland M, Rosenbluth G. Interprofessional teams: current trends and future directions. Pediatr Clin North Am. 2019;66 (4):739-750. doi:10.1016/j.pcl.2019.03.003

15. Keats JP. Leadership and teamwork: essential roles in patient safety. Obstet Gynecol Clin North Am. 2019;46(2):293-303. doi:10.1016/j.ogc.2019.01.008

16. Smith T, Fowler-Davis S, Nancarrow S, Ariss SMB, Enderby P. Leadership in interprofessional health and social care teams: a literature review. Leadersh Health Serv (Bradf Engl). 2018;31 (4):452-467. doi:10.1108/LHS-06-2016-0026

17. Eddy K, Jordan Z, Stephenson M. Health professionals' experience of teamwork education in acute hospital settings: a systematic review of qualitative literature. JBI Database System Rev Implement Rep. 2016;14(4):96-137. doi:10.11124/JBISRIR-2016-1843
18. Research AIf. TeamSTEPPS Teamwork Perceptions Questionnaire (T-TPQ) Manual. Washington, DC: Agency for Healthcare Research and Quality; 2010.

19. Tilden VP, Eckstrom E, Dieckmann NF. Development of the assessment for collaborative environments (ACE-15): a tool to measure perceptions of interprofessional "teamness". J Interprof Care. 2016;30(3):288-294. doi:10.3109/13561820.2015.1137891

20. Fraher EP, Ricketts TC, Lefebvre A, Newton WP. The role of academic health centers and their partners in reconfiguring and retooling the existing workforce to practice in a transformed health system. Acad Med. 2013;88(12):1812-1816. doi:10.1097/ACM.0000000000000024

21. WHO. Global strategy on human resources for health: workforce 2030. Geneva: World Health Organisation; 2016. Available from: https://www.who.int/hrh/resources/pub_globstrathrh-2030/en/. Accessed July 15, 2020.
Journal of Multidisciplinary Healthcare

\section{Publish your work in this journal}

The Journal of Multidisciplinary Healthcare is an international, peerreviewed open-access journal that aims to represent and publish research in healthcare areas delivered by practitioners of different disciplines. This includes studies and reviews conducted by multidisciplinary teams as well as research which evaluates the results or conduct of such teams or healthcare processes in general. The journal
Dovepress

covers a very wide range of areas and welcomes submissions from practitioners at all levels, from all over the world. The manuscript management system is completely online and includes a very quick and fair peer-review system. Visit http://www.dovepress.com/testimonials. php to read real quotes from published authors. 